\title{
Integração entre os Parâmetros Petrofísicos e Petrográficos em Arenitos do Grupo Itararé da Bacia do Paraná
}

\author{
Carlos André Maximiano da Silva - Universidade Federal do Espírito Santo - UFES \\ Giovanni Chaves Stael - Observatório Nacional - ON
}

Copyright 2018, SBGf - Sociedade Brasileira de Geofísica

Este texto foi preparado para a apresentação no VIII Simpósio Brasileiro de Geofísica, Salinópolis, 18 a 20 de setembro de 2018. Seu conteúdo foi revisado pelo Comitê Técnico do VIII SimBGf, mas não necessariamente representa a opinião da SBGf ou de seus associados. É proibida a reprodução total ou parcial deste material para propósitos comerciais sem prévia autorização da SBGt.

\section{Resumo}

Este trabalho apresenta um estudo integrado entre os métodos petrofísicos e petrográficos realizados em amostras de arenitos provenientes de dez furos de sondagens do Grupo Itararé, Bacia do Paraná. Foram caracterizadas as propriedades petrofísicas de rotina das amostras, tais como: porosidade efetiva e permeabilidade absoluta. A partir dos resultados obtidos, notou-se uma variabilidade nos valores de porosidade entre $11,1 \mathrm{e}$ $21,4 \%$ na petrofísica, e de 9,8 a $20,0 \%$ na petrográfica. Os valores de porosidades obtidos pelos métodos petrográficos foram, normalmente, menores do que os obtidos pela petrofísica. Isto ocorreu devido à presença de microporosidade, dificultando a passagem de fluido de preenchimento.

\section{Introdução}

Uma das questões de maior interesse para o setor petrolífero é a quantidade de hidrocarboneto contida em uma rocha reservatório. Uma aproximação inicial é a quantificação da fração volumétrica disponível para a acumulação de fluidos (água, óleo e gás) na formação. Essa quantidade é dependente do volume de poros existente em uma rocha reservatório e conseqüentemente irá influenciar na permeabilidade, assim como na maior parte das propriedades físicas da rocha (Lemos, 2004). A porosidade e a permeabilidade de rochas reservatórios podem ser estimadas a partir de testes laboratoriais em testemunhos (método direto) ou através da operação de perfilagem (método indireto). Essas propriedades podem determinar a viabilidade econômica de um determinado reservatório de hidrocarbonetos. Normalmente tais propriedades são obtidas utilizando-se experimentos laboratoriais, consumindo um tempo considerável, com custos muitas vezes elevados.

O termo "petrofísica" foi introduzido por Archie (1950) para descrever "o estudo das propriedades físicas das rochas que dizem respeito à distribuição de fluidos em seus espaços porosos". Essas propriedades são determinadas realizando-se experimentos em laboratório utilizando-se amostras (plugues) extraídos de furos de sondagens em rochas reservatórios com o objetivo de entender o sistema poroso dessas rochas e viabilizar os processos de exploração de hidrocarbonetos (Freire et al., 2010).

Segundo Milani et al., (2007) a Bacia do Paraná é uma ampla região sedimentar do continente sul-americano que inclui porções territoriais do Brasil meridional, Paraguai oriental, nordeste da Argentina e norte do Uruguai, totalizando uma área que se aproxima dos 1,5 milhão de quilômetros quadrados. O Grupo Itararé, depositado na Bacia do Paraná é uma unidade litoestratigráfica permo-carbonífera com aproximadamente $1,5 \mathrm{~km}$ de espessura de sedimentos registrando uma influência de condições glaciais na bacia.

Do ponto de vista exploratório, o Grupo Itararé representa um dos intervalos mais importantes da Bacia do Paraná, pois está associado a diversas ocorrências de bens minerais e energéticos como água subterrânea, petróleo e carvão (Artur \& Soares, 2002). Apesar de ser uma área largamente estudada e conhecida, ainda carece de dados petrofísicos que estejam publicados e disponíveis, de modo que esta pesquisa possa fornecê-los. A prospecção e explotação desses recursos dependem de um bom entendimento da arquitetura estratigráfica, da paleogeografia regional e do entendimento dos sistemas porosos das rochas reservatórios.

\section{Metodologia}

Os métodos empregados compreenderam a integração entre laboratórios com a finalidade de caracterizar as propriedades petrofísicas e petrográficas em amostras de arenitos provenientes de testemunhos de furos sondagens realizados na Bacia do Paraná e que foram cedidas gentilmente pela CPRM (Araraquara). A confecção das amostras, a limpeza química e a caracterização das propriedades petrofísicas do meio poroso a partir de porosímetro e permeâmetro de expansão a gás, foram realizados no laboratório de petrofísica do Observatório Nacional - LabPetrON, e as técnicas petrográficas, as confecções e imageamentos de lâminas foram realizadas no laboratório de Geologia Sedimentar - Lagesed na UFRJ.

Petrofísica de rotina

Para a realização deste trabalho, foram estudadas dez amostras de arenitos bem consolidados do Grupo Itararé - Bacia do Paraná. As mesmas foram cortadas $(5,2 \mathrm{~cm}$ de comprimento por $3,8 \mathrm{~cm}$ de diâmetro), limpas, secas, medidas (dimensões e massa), fotografadas e catalogadas no LabPetrON, conforme a Figura 1. 


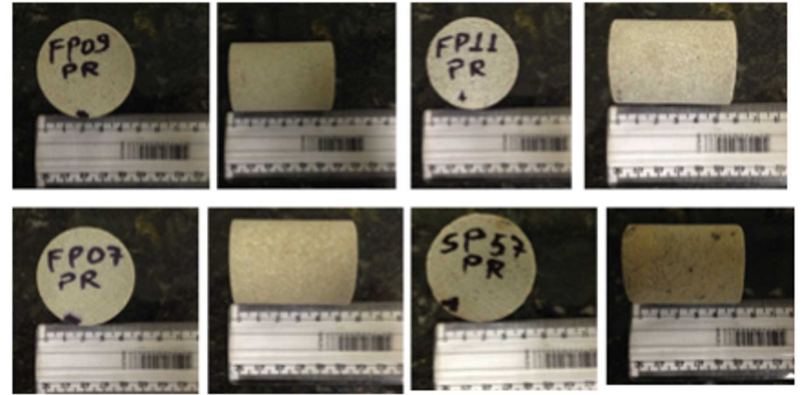

Figura 1. Fotos de alguns plugues utilizados nos ensaios petrofísicos e petrográficos.

Após os procedimentos iniciais, foram feitas as caracterizações petrofísicas de rotina das amostras quanto às suas propriedades permoporosas, as quais mensuraram os valores de porosidade efetiva e permeabilidade absoluta, a diferentes pressões de confinamento, simulando condições de reservatório.

Análise Petrográfica

A avaliação e a descrição através da microscopia convencional (microscópio óptico) foram realizadas sobre lâminas petrográficas após a impregnação com resina epóxi sob vácuo em todas as amostras, a fim de preencher os poros e evitar a desestruturação da rocha. Foi utilizado azul de metileno para a impregnação nas partes porosas que foram visualizados em lâminas, Figura 2.

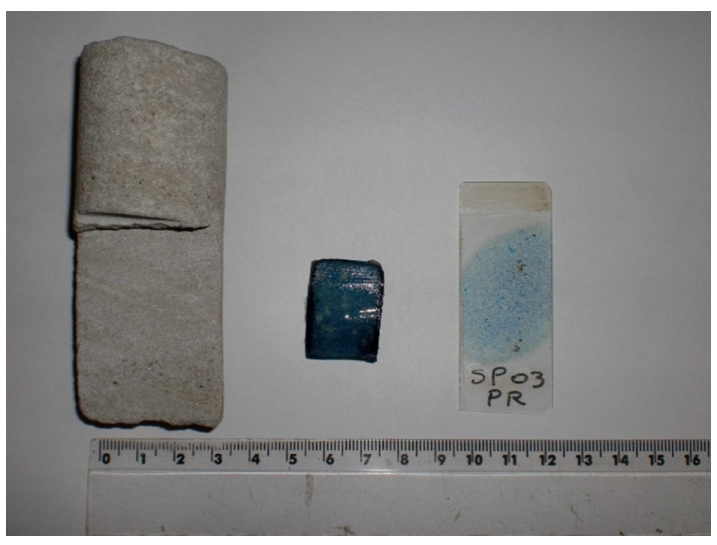

Figura 2. Plugue da rocha consolidada SP-03-PR; resina epóxi azul; lâmina delgada após o processo de impregnação da resina em seus poros.

A análise petrográfica objetivou a determinação das várias proporções dos minerais presentes nas rochas e a estimativa da porosidade a partir de imagens digitais (software IMAGEJ).

\section{Resultados}

A Tabela 1 mostra os dados de profundidade, porosidade e permeabilidade obtidos nos laboratórios de petrografia e Petrofísica para cada amostra estudada.

Tabela 1. Dados experimentais petrofísicos e petrográficos, em que: "Porosidade Lab" referece a petrofísica e "Porosidade Lam" obtida por lâminas petrográficas.

\begin{tabular}{l|c|c|c|c}
\hline Amostras & Profundidade & $\begin{array}{l}\text { Porosidade Lab (\%) } \\
\text { (porosímetro) }\end{array}$ & $\begin{array}{l}\text { Porosidade Lam (\%) } \\
\text { (lâmina) }\end{array}$ & $\begin{array}{l}\text { Permeabilidade } \\
\text { (mD) }\end{array}$ \\
\hline SP57PR & 445 & 14,847 & 13,092 & 1,02 \\
\hline SP43PR & 495 & 17,347 & 17,162 & 1,07 \\
\hline SP55PR & 694 & 15,573 & 15,007 & 48,7 \\
\hline FP09PR & 448 & 19,702 & 19,153 & 269 \\
\hline FP11PR & 603 & 17,008 & 16,154 & 99,5 \\
\hline FP07PR & 379 & 21,16 & 19,998 & 433 \\
\hline FP01PR & 368 & 11,084 & 9,789 & 0,241 \\
\hline FP04PR & 420 & 16,908 & 13,567 & 152 \\
\hline SP03PR & 470 & 21,437 & 18,398 & 572 \\
\hline FP05PR & 320 & 20,92 & 16,451 & 236 \\
\hline
\end{tabular}

A estimativa da porosidade a partir das imagens digitais petrográficas corroboraram com os valores de referência de porosidade determinados pelo método a gás, Figura 3.

$$
\text { Porosidade }(\Phi)_{L A M} \times \text { Porosidade }(\Phi)_{\angle A B}
$$

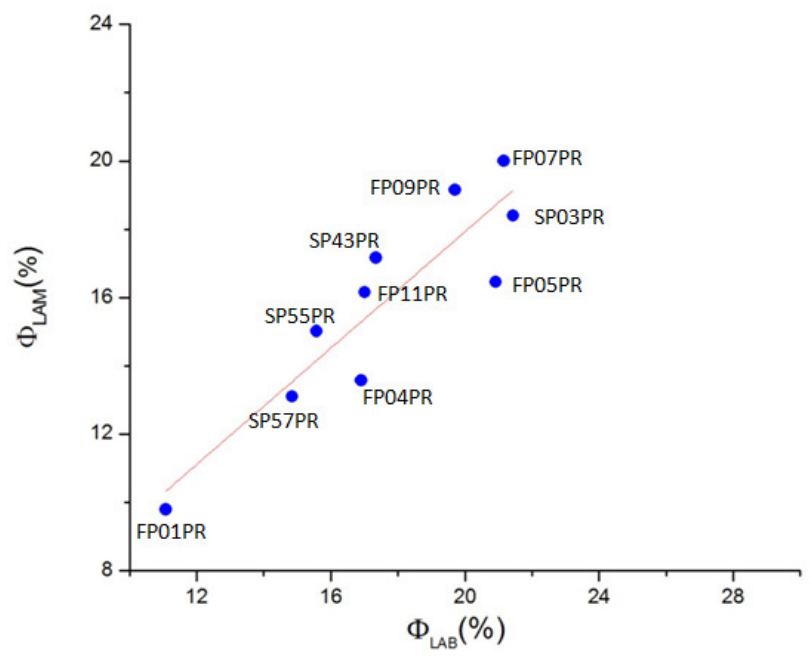

Figura 3. Correlação da porosidade (porosímetro) com a porosidade (lâmina).

Em relação à permeabilidade a gás observou-se que as amostras SP57PR e SP43PR apresentaram valores bastante baixos, o que foi testificado pelas imagens das análises petrográficas por apresentarem poros muito pequenos, possuindo pouquíssima conectividade.

Os resultados das propriedades de permeabilidade relativa e porosidade absoluta (porosímetro) foram 
comparados entre si, com objetivo de estabelecerem uma relação entre elas, Figura 4.

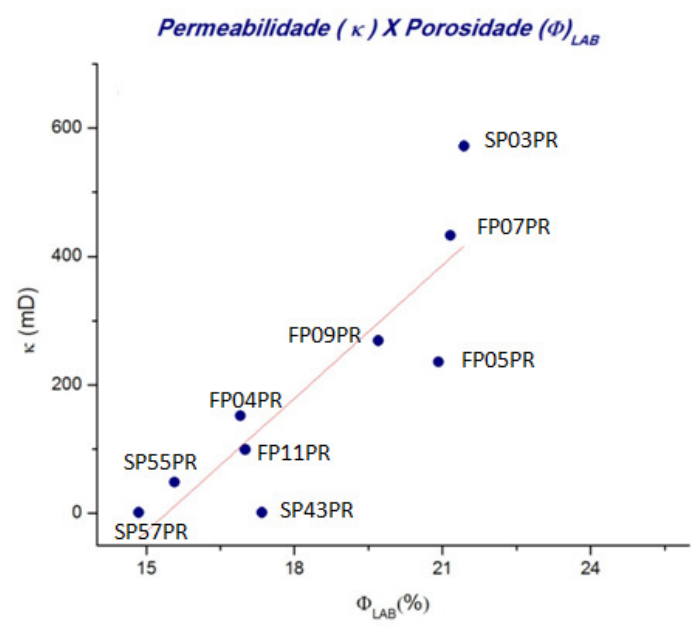

Figura 4. Correlação da permeabilidade com a porosidade (porosímetro).

Os arenitos de baixa permeabilidade apresentaram valores compatíveis com aqueles formados predominantemente por arenitos finos e muito finos argilosos. Assim, amostras com valores superiores a $100 \mathrm{mD}$ foram consideradas como bons reservatórios. Desprezando os arenitos com permeabilidades inferiores, pôde-se definir uma tendência linear entre a porosidade e a permeabilidade.

Apesar do baixo fator de correlação no gráfico porosidade-profundidade, observa-se uma tendência na diminuição dos valores de porosidade em relação à profundidade em função do grau de compactação oferecido pela carga litoestática (Figura 5).

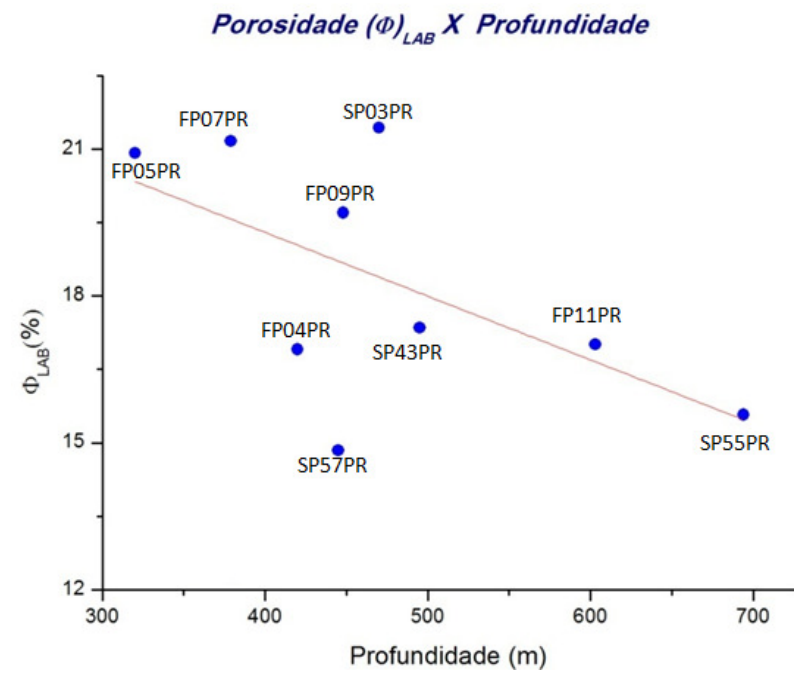

Figura 5. Correlação da porosidade (porosímetro) com a profundidade.
Considerando que no presente projeto a profundidade das amostras é relativamente rasa, ou seja, com uma profundidade máxima em torno de 694 metros de profundidade, as amostras apresentaram uma tendência linear.

\section{Conclusões}

Com base nos dados obtidos pelos métodos petrofísicos e petrográficos realizados nas amostras de arenitos do grupo Itararé da Bacia do Paraná concluiu-se que a variação dos valores de porosidade pelos métodos (porosímetro a gás) $11,1 \%$ e $21,4 \%$ e (lâmina) $9,8 \%$ e $20,0 \%$, está presente nos arenitos com granulometria média a muito fina.

Para a propriedade de permeabilidade observou-se uma oscilação de valores na faixa de $0,241 \mathrm{mD}$ a $572 \mathrm{mD}$, em que os resultados mais baixos referem-se aos arenitos de granulometria muito fina a fina comportando-se como barreiras naturais a passagem de fluidos, em função das gargantas de poros mais estreitas, não ocorrendo o mesmo com os arenitos de granulometria média, como observados nas lâminas.

Recomenda-se testar este conjunto de técnicas em outros potenciais reservatórios, principalmente com a finalidade de detectar uma possível dependência entre os poços estudados, aprimorando o entendimento do sistema poroso de determinadas formações, auxiliando na tomada de decisão.

\section{Agradecimentos}

Os autores agradecem pelo apoio a este trabalho à CPRM (Araraquara) pela cessão dos plugues de furos de sondagens na Bacia do Paraná, ao Observatório Nacional (ON) pela infra-estrutura laboratorial para a aquisição petrofísica e também à UFRJ pela confecção e análise das lâminas petrográficas.

\section{Referências}

Archie, G.E. Introduction to Petrophysics of Reservoir Rocks. Bull. Amer. Assoc. Petrl.Geolog.; 34(5): 943-961, 1950.

Artur, P. C.; Soares, P. C. Paleoestruturas e petróleo na Bacia do Paraná, Brasil. Revista Brasileira de Geociências. 32(4):433-448, dezembro de 2002.

Freire, R.; Nascimento, A.C.; Denicol, P.S.; Beneduzi, C. "Fluxo de trabalho na avaliação petrofísica de poços", In: Simpósio Brasileiro de Geofísica, SBGF_2459, Brasília, DF, Brasil, Nov. 2010.

Lemos, R. S. Estudo Sobre a Viabilidade do Cálculo da Porosidade com Base em um Conjunto Reduzido de perfis e sua Aplicação na Bacia de Almada/BA. Dissertação (Mestrado em Engenharia de Reservatório e de Exploração) - Universidade Estadual do Norte Fluminense Darcy Ribeiro, (123p), 2004. 
Milani, E. J.: França, A. B.; Fernandes, L. A.; Souza, A. P.; Melo, J. H. G. Bacia do Paraná. Boletim de Geociências da PETROBRAS, Rio de Janeiro, v 15, n. 2, p. 265-288, maio/Nov. 2007.

Surmas, R.; Compan, A. L. M.; Cruz, D. A.; Camargo, H. V. R.; Skinner, R.; Machado, V. F. "Petrofísica de Laboratório - Estado da Arte e Perspectivas", In: Simpósio Brasileiro de Geofísica, SBGF-2487, Brasília, DF, Brasil, Nov. 2010. 